\title{
Synthesis and Characterization of Novel Aromatic Polyamides and Polyimides Derived from 2,3-Di(3-aminophenyl)quinoxaline
}

\author{
Fumihiko Akutsu, ${ }^{\dagger}$ Mari InOKı, Kiminori Araki, Yoshio Kasashima, \\ Kiyoshi NARUCHI, and Masatoshi MiURA \\ Department of Applied Chemistry, Faculty of Engineering, Chiba University, \\ Yayoi-cho 1-33, Inage-ku, Chiba-shi 263, Japan
}

(Received December 16, 1996)

\begin{abstract}
A novel aromatic diamine 2,3-di(3-aminophenyl)quinoxaline (DAPQ) was prepared from benzil through three steps. New aromatic polyamides were synthesized by the direct polycondensation of DAPQ and several aromatic dicarboxylic acids. The polyamides were obtained almost quantitatively. The inherent viscosities ranged from 0.49 to $0.56 \mathrm{dl} \mathrm{g}^{-1}$. The glass transition temperatures $\left(T_{\mathrm{g}} \mathrm{s}\right)$ of the polyamides ranged from 258 to $291^{\circ} \mathrm{C}$, and the temperatures at $10 \%$ weight loss $\left(T_{\mathrm{d} 10} \mathrm{~s}\right)$ ranged between 515 and $546^{\circ} \mathrm{C}$. Novel aromatic polyimides were synthesized by the ring-opening polyaddition of several aromatic tetracarboxylic dianhydrides to DAPQ, followed by thermal cyclodehydration. The polyamic acids indicated the inherent viscosities of $0.28-1.13 \mathrm{dl} \mathrm{g}^{-1} . T_{\mathrm{g}} \mathrm{s}$ of the polyimides ranged between 263 and $298^{\circ} \mathrm{C}$, and $T_{\mathrm{d} 10} \mathrm{~s}$ were above $550^{\circ} \mathrm{C}$. The polyamides and polyimides were soluble in several organic solvents such as $m$-cresol.
\end{abstract} KEY WORDS Aromatic Polyamides / Aromatic Polyimides / Solubility / Thermal Properties /

Aromatic polyamides and polyimides have high thermal resistance and excellent mechanical properties. Therefore, these polymers are applied in various fields as high-performance engineering plastics. ${ }^{1,2}$ However, an important industrial problem is their low processability, which is caused by the poor solubility in many organic solvents and by the high melting points and glasstransition temperatures. The improvement of their solubility is consequently accompanied by lowering high thermal properties largely. One of the effective method without lowering high thermal properties is known to be the introduction of rigid and zigzag structures to main chains of polymers. ${ }^{3-12}$ We previouly reported the polyamides and polyimides containing rigid and zigzag structures, such as the combination of 1,4-phenylene unit with 1,2-heteroarylene units, possessed high thermal behavior as well as good solubility. ${ }^{13-20}$

In this article, novel aromatic polyamides 1 and polyimides 2 containing 2,3-di(1,3-phenylene)quinoxaline structure, as shown in Scheme 1, were synthesized and their properties were examined. Aromatic polyamides and polyimides introduced 2,3-di(1,4-phenylene)quinoxaline structure were found to indicate the high thermal properties and good solubility. ${ }^{14,17,20}$ The introduction of 1,3-phenylene unit, instead of 1,4-phenylene unit, to the polymer backbone is known to be effective against the improvement of the solubility of polymers. As the monomer, a new aromatic diamine having 2,3-quinoxalinediyl structure as well as 1,3-phenylene unit, 2,3di(3-aminophenyl)quinoxaline (DAPQ) was prepared, and the polyamides and polyimides were synthesized from DAPQ. In addition, these properties were compared with those of polymers containing 2,3-di(1,4phenylene)quinoxalinediyl structure ${ }^{14,20}$ in order to investigate a structural effect on properties of polyamides and polyimides.

\footnotetext{
† To whom all correspondence should be addressed.
}
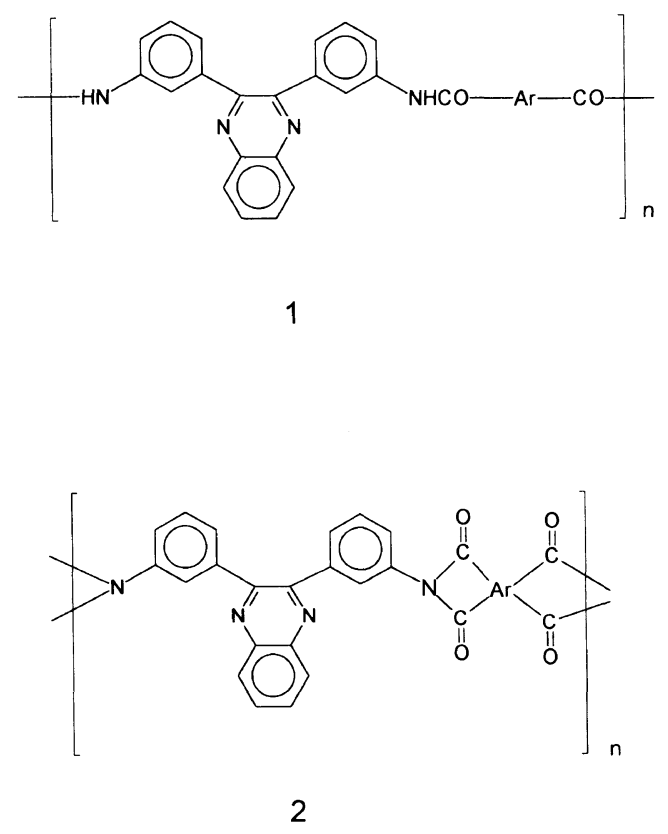

Scheme 1.

\section{EXPERIMENTAL}

\section{2,3-Di(3-nitrophenyl)quinoxaline 5}

In a flask equipped with a condenser was added $53 \mathrm{ml}$ of fuming nitric acid $(d=1.52)$, and then $40.4 \mathrm{~g}(0.19 \mathrm{~mol})$ of benzil 3 (Tokyo Kasei Kogyo Co., Ltd.) was added little by little during cooling with an ice bath. The mixture was refluxed for $5 \mathrm{~h}$. After cooling to room temperature, the reaction mixture was poured into an ice water for precipitation. The precipitate was washed with water, and dried under reduced pressure. Crude yield $82 \%$. IR (KBr, disk) $1680(\mathrm{C}=\mathrm{O}), 1510$ and $1350 \mathrm{~cm}^{-1}$ (N-O).

In a flask were added $720 \mathrm{ml}$ of acetic acid, $112.5 \mathrm{~g}$ $(0.38 \mathrm{~mol})$ of the crude nitration product, and $41.6 \mathrm{~g}$ $(0.39 \mathrm{~mol})$ of $o$-phenylenediamine. The mixture was refluxed for $5 \mathrm{~h}$. After cooling to room temperature, the 
formed precipitate was collected by filtration, recrystallized from acetic acid three times to give pale brown needles; mp $213-214^{\circ} \mathrm{C}$. Yield from $351 \%$. IR ( $\mathrm{KBr}$, disk) $1480 \mathrm{~cm}^{-1}(\mathrm{C}=\mathrm{N})$.

Anal. Calcd for $\mathrm{C}_{20} \mathrm{H}_{12} \mathrm{~N}_{4} \mathrm{O}_{4}$ (372.3): C, 64.51\%; H, $3.25 \%$; N, $15.05 \%$. Found : C, 64.56\%; H, 3.35\%; N, $14.98 \%$.

\section{$D A P Q$}

In a 50-ml four-necked flask equipped with a nitrogen inlet, a reflux condenser, a magnetic stirrer bar and a thermometer were placed $200 \mathrm{ml}$ of conc. hydrochloric acid and $101.2 \mathrm{~g}(0.45 \mathrm{~mol})$ of stannous chloride, and dissolved on heating. The solution was cooled with an ice bath, and $20.84 \mathrm{~g}$ of $5(56.0 \mathrm{mmol})$ was added. The mixture was stirred for $2 \mathrm{~h}$ during chilling, then for 1 day at room temperature under a nitrogen atmosphere. The reaction mixture was filtrated, and added to $900 \mathrm{ml}$ of a $15-\mathrm{wt} \%$ aqueous solution of sodium hydroxide to obtain a yellow precipitate. The product was collected by filtration, and washed with an aqueous solution of sodium hydroxide, and with water. The product was dissolved in $50 \mathrm{ml}$ of $3 \mathrm{M} \mathrm{HCl}$, filtrated on heating, poured into a $5-\mathrm{wt} \%$ aqueous solution of sodium hydroxide for precipitation. The product was washed with water, and dried under reduced pressure. The crude product was recrystallized from aqueous methanol to afford yellow needles; mp $232-233^{\circ} \mathrm{C}$. Yield $81 \%$.

IR (KBr, disk) $3432,3320 \mathrm{~cm}^{-1}(\mathrm{~N}-\mathrm{H})$.

${ }^{1} \mathrm{H}$ NMR $\left(400 \mathrm{MHz}, \mathrm{DMSO}-d_{6}\right): \delta=5.19(\mathrm{~s} ; 4 \mathrm{H}$, $\left.-\mathrm{NH}_{2}\right), 6.48(\mathrm{~m} ; 2 \mathrm{H}, \mathrm{Ar}-\mathrm{H}), 6.58(\mathrm{~m} ; 2 \mathrm{H}, \mathrm{Ar}-\mathrm{H}), 6.94$ (m; 4H, Ar-H), 7.85 (m; 2H, quinoxaline-H), $8.10(\mathrm{~m}$; $2 \mathrm{H}$, quinoxaline- $\mathrm{H})$.

${ }^{13} \mathrm{C}$ NMR (100 MHz, DMSO- $\left.d_{6}\right): \delta=114.29\left(\mathrm{Ar}-\mathrm{C}_{2}\right)$, $114.68\left(\mathrm{Ar}-\mathrm{C}_{4}\right), 117.36\left(\mathrm{Ar}-\mathrm{C}_{6}\right), 128.18$ (quinoxaline$\mathrm{C}_{6}$ ), 128.63 (quinoxaline- $\mathrm{C}_{5}$ ), $130.02\left(\mathrm{Ar}_{\mathrm{r}} \mathrm{C}_{5}\right), 139.64$ $\left(\mathrm{Ar}-\mathrm{C}_{1}\right), 140.21$ (quinoxaline- $\left.\mathrm{C}_{9}\right), 148.49\left(\mathrm{Ar}-\mathrm{C}_{3}\right), 153.73$ (quinoxaline- $\mathrm{C}_{2}$ ).

Anal. Calcd for $\mathrm{C}_{20} \mathrm{H}_{16} \mathrm{~N}_{4}$ (312.4): C, 76.90\%; H, $5.16 \% ; \mathrm{N}, 17.94 \%$. Found : C, 76.63\%; H, 5.09\%; N, $17.92 \%$.

\section{Other Monomers}

Aromatic dicarboxylic acids, such as terephthalic acid (6a), isophthalic acid (6b), 4,4'-biphenyldicarboxylic acid (6c), were obtained commercially, and used after recrystallization (6a and $\mathbf{6 b}$, from methanol/water; $\mathbf{6 c}$, from benzene). Pyromellitic dianhydride (9d), 3,3',4,4'-biphenyltetracarboxylic dianhydride (9e), and 4,4'-carbonyldiphthalic anhydride (9f) were obtained commercially, recrystallized from acetic anhydride, and sublimated under reduced pressure just before polymerization.

\section{Direct Polycondensation of Polyamides}

A typical procedure is as follows. Into a four-necked $10-\mathrm{ml}$ reaction tube equipped with a reflux condenser, a mechanical stirrer, and a nitrogen gas inlet having a calcium-chloride tube were placed $0.075 \mathrm{~g}$ lithium chloride, $0.225 \mathrm{~g}$ of calcium chloride, and $3.75 \mathrm{ml}$ of 1 -methyl-2pyrrolidone (NMP). The mixture was heated with stirring under a nitrogen atmosphere until the salts were dissolved. After the mixture was cooled to room temperature, $0.249 \mathrm{~g}$ of isophthalic acid $(1.50 \mathrm{mmol}), 0.788 \mathrm{ml}$ of triphenyl phosphite $(3.00 \mathrm{mmol})$, and $0.75 \mathrm{ml}$ of pyridine were added. The mixture was stirred for $10 \mathrm{~min}$, and $0.469 \mathrm{~g}$ of DAPQ $(1.50 \mathrm{mmol})$ were added. The reaction mixture was heated at $115^{\circ} \mathrm{C}$ for $5 \mathrm{~h}$ with stirring. It was then cooled and poured into aqueous methanol (1:1 by volume). The precipitate was collected on a glass filter, washed with methanol in reflux and dried under reduced pressure. Yield $97 \%$.

$\eta_{\text {inh }}=0.56 \mathrm{dlg}^{-1}\left(0.5 \mathrm{~g} \mathrm{dl}^{-1}\right.$ in conc. sulfuric acid at $30^{\circ} \mathrm{C}$ ). IR (KBr, disk) $1664,1536 \mathrm{~cm}^{-1}$ (amide I, II).

Anal. Calcd for $\left(\mathrm{C}_{28} \mathrm{H}_{18} \mathrm{~N}_{2} \mathrm{O}_{4}\right)_{n}(442.5)_{n}$ : C, 76.00\%; H, 4.10\%; N, 12.67\%. Found: C, 74.67\%; H, 4.06\%; N, $12.18 \%$.

Other polyamides were synthesized by a similar procedure.

\section{Ring-Opening Polyaddition and Cyclodehydration of Poly- imides}

A typical procedure is as follows. In a four-necked $10-\mathrm{ml}$ reaction tube equipped with a mechanical stirrer and a nitrogen inlet having a calcium-chloride tube, were placed $0.469 \mathrm{~g}$ of DAPQ $(1.5 \mathrm{mmol})$ and $3.0 \mathrm{ml}$ of $N, N$-dimethylacetamide (DMAc). The mixture was chilled to $-18^{\circ} \mathrm{C}$, to which were added $0.483 \mathrm{~g}$ of $9 \mathrm{f}$ $(1.5 \mathrm{mmol})$ and $2.0 \mathrm{ml}$ of DMAc. It was stirred for $5 \mathrm{~h}$, and then was allowed to stand over night at room temperature. A $0.40-\mathrm{ml}$ portion of the reaction mixture was removed for viscosity measurement. The remaining mixture was spread on a glass plate and the solvent was removed at $90^{\circ} \mathrm{C}$. The obtained film was dried under reduced pressure at $60^{\circ} \mathrm{C}$. The inherent viscosity of the polyamic acid $10 \mathrm{f}$ was $0.89 \mathrm{dlg}^{-1}\left(0.5 \mathrm{~g} \mathrm{dl}^{-1}\right.$ in DMAc at $\left.30^{\circ} \mathrm{C}\right)$. IR (film) $3500-2800(\mathrm{O}-\mathrm{H}, \mathrm{N}-\mathrm{H}), 1720(\mathrm{C}=$ O), 1622, 1554 (amide I, II) $\mathrm{cm}^{-1}$.

Thermal cyclodehydration of polyamic acid $\mathbf{1 0 f}$ was performed by heating at $250^{\circ} \mathrm{C}$ for $2 \mathrm{~h}$ in an electric furnace under reduced pressure. As soon as heating was over, the product was taken out of an electric furnace and cooled to room temperature. IR (film) 1776, 1710 (imide $\mathrm{C}=\mathrm{O}$ ), 1370 (imide $\mathrm{C}-\mathrm{N}$ ) $\mathrm{cm}^{-1}$.

Anal. Calcd for $\left(\mathrm{C}_{37} \mathrm{H}_{18} \mathrm{~N}_{4} \mathrm{O}_{5}\right)_{n}(598.6)_{n}$ : C, $74.24 \%$; H, 3.03\%; N, 9.36\%. Found: C, 73.14\%; H, 3.19\%; N, $9.00 \%$.

Other polyimides were synthesized by a similar procedure.

\section{Measurements}

Glass-transition temperatures $\left(T_{\mathrm{g}} \mathrm{s}\right)$, temperatures at $10 \%$ weight loss $\left(T_{\mathrm{d} 10} \mathrm{~s}\right)$ and weight residues at $600^{\circ} \mathrm{C}$ were obtained by thermogravimetry (TG)-differential scanning calorimetry (DSC) (Rigaku TG-DSC 8055D1) under the following conditions: heating rate, $10 \mathrm{~K} \mathrm{~min}^{-1}$; in a nitrogen atmosphere. $T_{\mathrm{g}} \mathrm{s}$ were determined by second scannings. IR spectra were recorded on a Hitachi 27030 spectrophotometer. Wide angle X-ray diffraction patterns were obtained for specimens on a Rigaku XG $\mathrm{X}$-ray diffraction apparatus with $\mathrm{Cu}-K_{\alpha}$ radiation (25 $\mathrm{kV}, 10 \mathrm{~mA}$ ) using virgin samples. NMR spectra were obtained with FT-NMR spectrometer (JEOL JNMGSX400). 


\section{RESULTS AND DISCUSSION}

\section{Monomer Synthesis}

Novel diamine DAPQ was synthesized from benzil (3) through three steps, as shown in Scheme 2. 3,3'-Dinitrobenzil (4) was not isolated because nitration of 3 gave the isomeric mixture ${ }^{21}$ and the purification by recrystallization was accompanied by lowering the yield largely. 2,3-Di(3-nitrophenyl)quinoxaline (5) was prepared by the reaction of the crude nitration product with $o$-phenylenediamine for the formation of a quinoxaline ring. ${ }^{22}$ DAPQ was obtained by the reduction of 5 using stannous chloride and hydrochloric acid. The product was identified by elemental analysis and spectroscopic data as DAPQ.
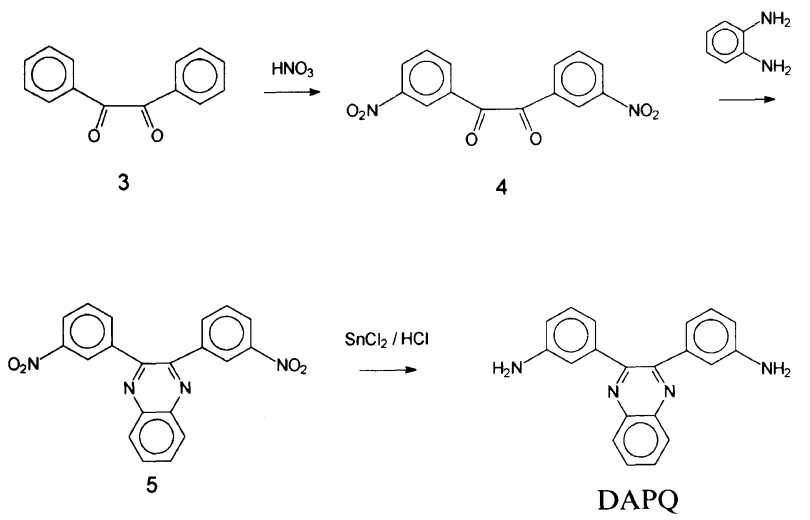

Scheme 2.

\section{Polyamide Synthesis}

Polyamides 1 were prepared by direct polycondensation of DAPQ with several aromatic dicarboxylic acids, such as terephthalic acid (6a), isophthalic acid (6b), and 4,4'-biphenyldicarboxylic acid (6c), using triphenyl phosphite, pyridine, lithium chloride, and calcium chlo-

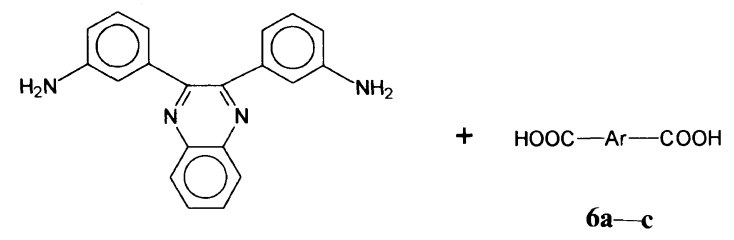

DAPQ

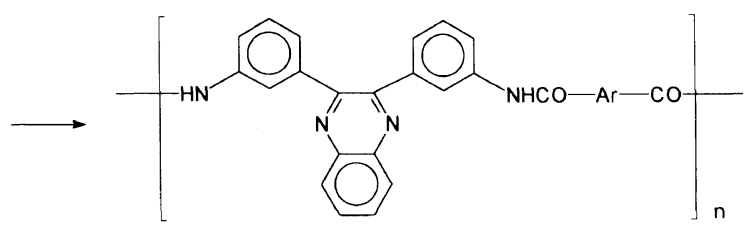

polyamide $1 \mathbf{1}-\mathbf{c}$

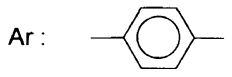

a

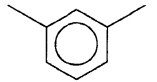

b

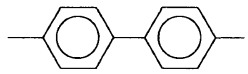

c
Scheme 3.
Table I. Results of polycondensations ${ }^{\mathrm{a}}$ and thermal properties of polyamides

\begin{tabular}{|c|c|c|c|c|c|}
\hline \multirow{2}{*}{ Polymer } & Yield & $\eta_{\mathrm{inh}}^{\mathrm{b}}$ & $T_{\mathrm{g}}^{\mathrm{c}}$ & $T_{\mathrm{d} 10}{ }^{\mathrm{d}}$ & \multirow{2}{*}{$\begin{array}{l}\text { Weight residue } \\
\text { at } 600^{\circ} \mathrm{C} / \%\end{array}$} \\
\hline & $\%$ & $\mathrm{dl} \mathrm{g}^{-1}$ & ${ }^{\circ} \mathrm{C}$ & ${ }^{\circ} \mathrm{C}$ & \\
\hline 1a & 98 & 0.49 & 268 & 546 & 85 \\
\hline $1 \mathrm{~b}$ & 97 & 0.56 & 258 & 528 & 85 \\
\hline 1c & 95 & 0.54 & 291 & 515 & 76 \\
\hline
\end{tabular}

a Polymerization was carried out with $1.50 \mathrm{mmol}$ of each monomer, $75 \mathrm{mg}$ of lithium chloride, $225 \mathrm{mg}$ of calcium chloride, $0.788 \mathrm{ml}$ of triphenyl phosphite, $0.75 \mathrm{ml}$ of pyridine, and $3.75 \mathrm{ml}$ of NMP at $115^{\circ} \mathrm{C}$ for $5 \mathrm{~h}$. The polymerizations proceeded in a homogeneous system. The obtained polyamides were pale yellow. ${ }^{\mathrm{b}}$ Inherent viscosity, measured in conc. sulfuric acid $\left(0.50 \mathrm{~g} \mathrm{dl}^{-1}\right)$ at $30^{\circ} \mathrm{C}$. ${ }^{c}$ Glass transition temperature, measured by DSC. ${ }^{d}$ Temperature at $10 \%$ weight loss, determined by $\mathrm{TG}$ in a nitrogen atmosphere. ${ }^{\mathrm{e}}$ Determined by TG in a nitrogen atmosphere.

ride as condensation agents, ${ }^{23-25}$ as shown in Scheme 3. All polycondensations proceeded in a homogeneous system. The obtained polymers were identified by elemental analysis and IR spectra. The IR spectra of the polymers showed characteristic amide absorptions near 1660 and $1540 \mathrm{~cm}^{-1}$. All polyamides were obtained almost quantitatively. The inherent viscosities of polyamides 1 ranged from 0.49 to $0.56 \mathrm{dl} \mathrm{g}^{-1}$. The results are shown in Table I.

\section{Thermal Properties and Solubility of Polyamides}

$T_{\mathrm{g}} \mathrm{s}$ were determined by differential scanning calorimetry (DSC). The temperatures at $10 \%$ weight loss $\left(T_{\mathrm{d} 10} \mathrm{~s}\right)$ and weight residues at $600^{\circ} \mathrm{C}$ were determined by thermogravimetry (TG). Thermal behavior of polyamides is summarized in Table I. $T_{\mathrm{g}} \mathrm{s}$ of polyamides 1 ranged from 258 to $291^{\circ} \mathrm{C}$. $T_{\mathrm{d} 10} \mathrm{~s}$ ranged between 515 and $546^{\circ} \mathrm{C}$, and weight residues at $600^{\circ} \mathrm{C}$ was above $76 \%$. The high thermal stability was due to the high ratio of aromatic rings in the polyamide structure and a thermally stable quinoxaline ring.

Solubilities in several organic solvents at $2.0 \%(\mathrm{w} / \mathrm{v})$ are tabulated in Table II. Polyamides 1 showed high solubility. In particular, polyamide $\mathbf{1 b}$ was soluble in conc. sulfuric acid, dimethylsulfoxide (DMSO), $N, N$ dimethylformamide (DMF), hexamethylphosphoric triamide (HMPA), 1-methyl-2-pyrrolidone (NMP), $N, N$ dimethylacetamide (DMAc), $m$-cresol, and pyridine at room temperature. X-Ray diffraction patterns showed that polyamides 1 were all amorphous. It was considered that the high solubility of $\mathbf{1}$ was due to the amorphous nature, induced by the introduction of zigzag and unsymmetrical 2,3-di(1,3-phenylene)quinoxaline structure to the polyamide backbone.

The solubility and $T_{\mathrm{g}} \mathrm{s}$ of 1 were compared with those of corresponding polyamides 7 having 2,3-di(1,4-phenylene)quinoxaline structure ${ }^{14}$ as shown in Scheme 4, respectively. $T_{\mathrm{g}} \mathrm{s}$ of polyamides 1 were lower than those of corresponding polyamides 7 , while having the almost equal values of the inherent viscosity. The solubility of 1 was higher than that of corresponding 7. The lower $T_{\mathrm{g}} \mathrm{s}$ and higher solubility of 1 were attributed to the more zigzag main-chain shape of polyamides 1 produced by the combination of 1,3-phenylene moiety and 2,3quinoxalinediyl unit. 
Table II. Solubilities ${ }^{\mathrm{a}}$ of polyamides and polyimides

\begin{tabular}{|c|c|c|c|c|c|c|c|c|}
\hline Polymer & Py & $m$-Cre & DMAc & NMP & HMPA & $\mathrm{HCOOH}$ & DMSO & $\mathrm{H}_{2} \mathrm{SO}_{4}$ \\
\hline 1a & \pm & + & + & + & + & \pm & + & + \\
\hline 1b & $\bar{t}$ & + & + & + & + & $\bar{t}$ & + & + \\
\hline 1c & - & \pm & \pm & \pm & \pm & \pm & \pm & + \\
\hline $2 d$ & \pm & + & \pm & + & \pm & + & - & + \\
\hline $2 e$ & $\overline{ \pm}$ & + & $\overline{-}$ & \pm & $\overline{-}$ & - & - & + \\
\hline $2 f$ & - & + & \pm & + & \pm & - & - & + \\
\hline
\end{tabular}

${ }^{a}$ Measured at $2.0 \%(\mathrm{w} / \mathrm{v})$. The symbols have the following meanings: + , soluble; \pm , partially soluble; - , insoluble. Py, pyridine; $m$-Cre, $m$-cresol; DMAc, $N, N$-dimethylacetamide; NMP, 1-methyl-2-pyrrolidone; HMPA, hexamethylphosphoric triamide; DMSO, dimethylsulfoxide.

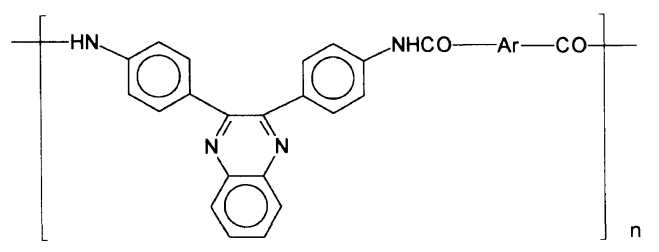

polyamide 7

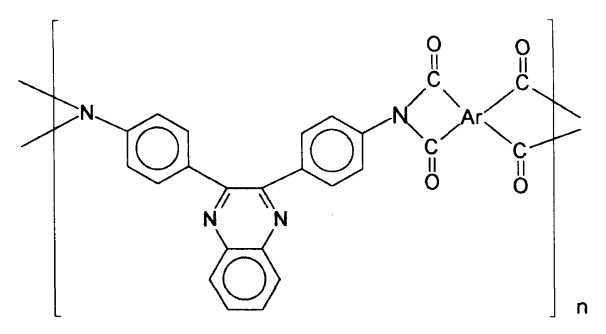

polyimide $\mathbf{8}$

Scheme 4.

Table III. Results of ring-opening polyadditions ${ }^{a}$ and thermal properties of polyimides

\begin{tabular}{|c|c|c|c|c|}
\hline \multirow{2}{*}{ Polyimide } & $\eta_{\text {inh }}{ }^{b}$ & $T_{\mathrm{g}}^{\mathbf{c}}$ & $T_{\mathrm{d} 10}^{\mathrm{d}}$ & \multirow{2}{*}{$\begin{array}{l}\text { Weight residue } \\
\text { at } 600^{\circ} \mathrm{C} / \%^{\mathrm{e}}\end{array}$} \\
\hline & $\mathrm{dl} \mathrm{g}^{-1}$ & ${ }^{\circ} \mathrm{C}$ & ${ }^{\circ} \mathrm{C}$ & \\
\hline $2 d$ & 0.28 & 298 & 550 & 77 \\
\hline $2 e$ & 1.13 & 286 & 579 & 86 \\
\hline $2 f$ & 0.89 & 263 & 566 & 84 \\
\hline
\end{tabular}

a Polymerization was carried out with $1.5 \mathrm{mmol}$ of each monomer and $5.0 \mathrm{ml}$ of DMAc at $-18^{\circ} \mathrm{C}$ for $5 \mathrm{~h}$. The obtained polyamic acids were yellow. ${ }^{\mathrm{b}}$ Inherent viscosity of the corresponding polyamic acid, measured in DMAc $\left(0.50 \mathrm{~g} \mathrm{dl}^{-1}\right)$ at $30^{\circ} \mathrm{C}$. ${ }^{\mathrm{c}}$ Glass transition temperature, measured by DSC. ${ }^{d}$ Temperature at $10 \%$ weight loss, determined by $\mathrm{TG}$ in a nitrogen atmosphere. ${ }^{\mathrm{e}}$ Determined by TG in a nitrogen atmosphere.

\section{Polyimide Synthesis}

Polyimides 2 were synthesized by the two-step procedure $^{26}$ as shown in Scheme 5. Polyamic acids $\mathbf{1 0}$ were prepared by the ring-opening polyaddition of aromatic tetracarboxylic dianhydrides to DAPQ, followed by thermal cyclodehydration under reduced pressure. Pyromellitic dianhydride (9d), 3, 3',4,4'-biphenyltetracarboxylic dianhydride (9e), and 4,4'-carbonyldiphthalic anhydride (9f) were used as the aromatic tetracarboxylic dianhydride monomers. The results of the ring-opening polyaddition were tabulated in Table<smiles>Nc1cccc(-c2nc3ccccc3[nH]2)c1</smiles><smiles>CC(C)(C)Nc1cccc(-c2nc3ccccc3nc2-c2cccc(NC(=O)C(C)(C)C(=O)O)c2)c1</smiles>

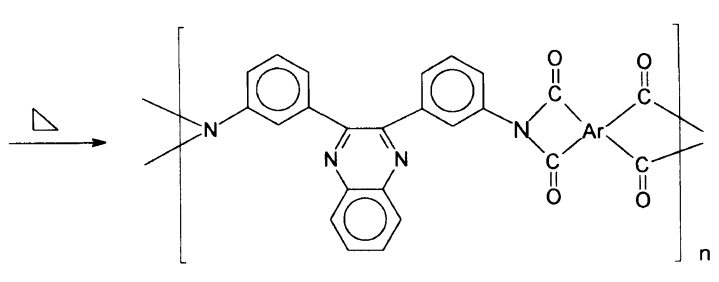

polyimide $2 \mathbf{d}-\mathbf{f}$

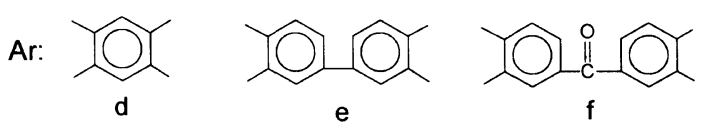

Scheme 5 .

III. All polyadditions proceeded in a homogeneous system. The inherent viscosities of polyamic acids $\mathbf{1 0}$ ranged from 0.28 to $1.13 \mathrm{dlg}^{-1}$. The reason for the irregular low inherent viscosity of $\mathbf{1 0 d}$ is not clear, which may be due to the lower reactivity of oligoamic acid caused by some steric effects.

The thermal cyclodehydrations of polyamic acids $\mathbf{1 0}$ were performed in an electric furnace at $250^{\circ} \mathrm{C}$ for $2 \mathrm{~h}$ under reduced pressure. The products were identified as polyimides 2 by IR spectroscopy and elemental analysis.

\section{Thermal Properties and Solubility of Polyimides}

Thermal properties of polyimides $\mathbf{2}$ are shown in Table III. $T_{\mathrm{g}} \mathrm{s}$ of polyimides 2 ranged from 263 to $298^{\circ} \mathrm{C}$. $T_{\mathrm{d} 10^{\circ}} \mathrm{S}$ of 2 was observed above $550^{\circ} \mathrm{C}$, and weight residues at $600^{\circ} \mathrm{C}$ of 2 ranged between 77 and $86 \%$. The solubility of polyimides 2 at $2.0 \%(\mathrm{w} / \mathrm{v})$ are indicated in Table II. Polyimides 2 showed good solubility. 2e was soluble in $m$-cresol and conc. sulfuric acid at room temperature. 
2d and $2 \mathbf{f}$ were further soluble in NMP. The introduction of zigzag and unsymmetrical 2,3-di(1,3-phenylene)quinoxaline structure was effective against the improvement of the solubility of aromatic polyimides. X-Ray diffraction patterns of $\mathbf{2}$ indicated the polyimides are all amorphous. The introduction of the zigzag and unsymmetrical structure to the polyimides caused the amorphous nature, which contributed to the improvement of the solubility.

Except for $\mathbf{2 d}$, the properties of $\mathbf{2}$ were compared with those of corresponding polyimides 8 containing 2,3di(1,4-phenylene)quinoxaline structure, ${ }^{20}$ as shown in Scheme 4 , of which the values of inherent viscosity were almost equal. The solubility of $\mathbf{2}$ was better than that of 8. $T_{\mathrm{g}} \mathrm{s}$ of $\mathbf{2}$ were lower than those of $\mathbf{8}$. These facts were attributed to the sparser molecular-chain packings of $\mathbf{2}$, induced by the introduction of more unsymmetrical and zigzag 2,3-di(1,3-phenylene)quinoxaline structure.

\section{CONCLUSION}

Novel aromatic polyamides and polyimides having 2,3-di(1,3-phenylene)quinoxaline structure in the main chain possessed the high solubility and high thermal stability, respectively.

Acknowledgments. The authors thank to Ms. Hiroko Seki, the Chemical Analysis Center, Chiba University, and Ms. Tomoko Doi, Graduate School of Science and Technology, Chiba University, for carrying out elemental analysis.

\section{REFERENCES}

1. P. E. Cassidy, "Thermally Stable Polymers," Dekker, New York, N.Y., 1980.

2. M. K. Ghosh and K. L. Mittal, "Polyimides," Dekker, New York, N.Y., 1996.
3. Y. Imai, N. N. Maldar, and M. Kakimoto, J. Polym. Sci., Polym. Chem. Ed., 23, 1797 (1985).

4. M. Kakimoto, Y. S. Negi, and Y. Imai, J. Polym. Sci., Polym. Chem. Ed., 23, 1787 (1985).

5. Y. Imai, N. N. Maldar, and M. Kakimoto, J. Polym. Sci., Polym. Chem. Ed., 22, 2189 (1985)

6. H. J. Jeong, Y. Oishi, M. Kakimoto, and Y. Imai, J. Polym. Sci., Part A, Polym. Chem., 28, 3293 (1990).

7. H. J. Jeong, Y. Oishi, M. Kakimoto, and Y. Imai, J. Polym. Sci., Part A, Polym. Chem., 29, 767 (1991).

8. G. Liou, Y. Oishi, M. Kakimoto, and Y. Imai, J. Polym. Sci., Part A, Polym. Chem., 29, 995 (1991).

9. H. J. Jeong, Y. Oishi, M. Kakimoto, and Y. Imai, J. Polym. Sci., Part A, Polym. Chem., 29, 39 (1991).

10. H. J. Jeong, M. Kakimoto, and Y. Imai, J. Polym. Sci., Part A, Polym. Chem., 29, 1691 (1991).

11. H. J. Jeong, A. Kobayashi, M. Kakimoto, and Y. Imai, Polym. J., 26, 99 (1994).

12. H. J. Jeong, A. Kobayashi, M. Kakimoto, and Y. Imai, Polym. J., 26, 373 (1994).

13. F. Akutsu, H. Hirata, H. Hayashi, M. Miura, and K. Nagakubo, Makromol. Chem., Rapid Commun., 6, 215 (1985).

14. F. Akutsu, H. Hayashi, M. Miura, and K. Nagakubo, Makromol. Chem., Rapid Commun., 6, 407 (1985).

15. F. Akutsu, H. Hayashi, M. Miura, and K. Nagakubo, Makromol. Chem., Rapid Commun., 6, 475 (1985).

16. F. Akutsu, H. Takeyama, M. Miura, and K. Nagakubo, Makromol. Chem., 186, 483 (1985).

17. F. Akutsu, K. Matsuo, N. Naruchi, and M. Miura, Polym. Commun., 30, 182 (1987).

18. F. Akutsu, A. Suzuki, F. Saitoh, K. Naruchi, M. Miura, and K. Nagakubo, Makromol. Chem., 188, 1253 (1987).

19. F. Akutsu, T. Kataoka, K. Naruchi, M. Miura, and K. Nagakubo, Polymer, 28, 1787 (1987).

20. F. Akutsu, S. Kuze, K. Matsuo, K. Naruchi, and M. Miura, Makromol. Chem. Rapid Commun., 11, 673 (1990).

21. E. A. Colson, J. Chem. Soc., 577 (1927).

22. T. van Es and O. G. Backberg, J. Chem. Soc., 1371 (1963).

23. F. Higashi, Y. Aoki, and Y. Taguchi, Makromol. Chem., Rapid Commun., 2, 329 (1981).

24. F. Higashi, S. Ogata, and Y. Aoki, J. Polym. Sci., Polym. Chem. Ed., 20, 2081 (1982).

25. F. Higashi, N. Akiyama, and S. Ogata, J. Polym. Sci., Polym. Chem. Ed., 21, 913 (1983).

26. C. E. Sroog, Macromol Rev., 11, 161 (1976). 